\title{
SEQUENTIAL AND CONDITIONAL COMPACTNESS \\ IN THE DUAL OF A BARRELLED SPACE
}

\author{
EDWARD G. OSTLING
}

\begin{abstract}
Let $E$ be a barrelled locally convex space and suppose $T_{Q}$ is a topology on the dual $E^{\prime}$ of $E$ which is admissible for the duality $\left(E, E^{\prime}\right)$. It is shown that each $T_{Q}$ sequentially compact subset of $E^{\prime}$ is $T_{Q}$ conditionally compact.
\end{abstract}

Let $X$ denote a Banach space and $r\left(X^{\prime}, X\right)$ the Mackey topology for the dual $X^{\prime}$ of $X$. J. Howard [1] used a result of Grothendieck to show that each $x\left(X^{\prime}, X\right)$ sequentially compact subset of $X^{\prime}$ is $x\left(X^{\prime}, X\right)$ conditionally compact. We give a direct proof of a more general result.

Let $E$ denote a locally convex topological vector space. A topology $T_{a}$ on the dual $E^{\prime}$ of $E$ is admissible for the duality $\left(E, E^{\prime}\right)$ if it is the topology of uniform convergence on a family $\mathbb{A}$ of subsets of $E$ satisfying conditions $\mathrm{B} 1-\mathrm{B} 3$ on p. 46 of [4]. Also, $\sigma\left(E^{\prime}, E\right)$ denotes the weak star topology on $E^{\prime}$, so that each admissible topology on $E^{\prime}$ is finer than $\sigma\left(E^{\prime}, E\right)$.

Theorem. Let $E$ be a barrelled space and suppose $T_{Q}$ is a topology on $E^{\prime}$ admissible for $\left(E, E^{\prime}\right)$. Then each $T_{Q}$ sequentially compact subset of $E^{\prime}$ is $T_{Q}$ conditionally compact.

Proof. By $[3,21.4(4)],\left(E^{\prime}, \sigma\left(E^{\prime}, E\right)\right)$ is a boundedly complete space. It follows from $[3,18.4,(4 b)]$ that $\left(E^{\prime}, T_{Q}\right)$ is boundedly complete. Let $A^{\prime}$ be a $T_{a}$ sequentially compact subset of $E^{\prime}$. Then $A^{\prime}$ is $T_{Q}$ countably compact, hence $T_{Q}$ totally bounded [3, 5.6 (3)]. It follows from [4, Lemma 3, p. 49] that the $T_{Q}$ closure $\bar{A}^{\prime}$ of $A^{\prime}$ is $T_{Q}$ totally bounded, hence $T_{Q}$ bounded and closed. Therefore, $\bar{A}^{\prime}$ is $T_{Q}$ complete, hence $T_{Q}$ compact.

Remarks. (1) Since a Banach space $X$ is barrelled and $x\left(X^{\prime}, X\right)$ is admissible for $\left(X, X^{\prime}\right)$, the result of [1] stated above is a special case of the Theorem.

Received by the editors August 27, 1973.

AMS (MOS) subject classifications (1970). Primary 46A07, 46A09, 46B99.

Key words and phrases. Mackey topology, conditionally compact, sequentially compact, barrelled, bornological, admissible topology. 
(2) As was shown in [1], there are barrelled spaces in which the converse of our result is false.

(3) By [2, Problem 19C], a bornological space $E$ in which the closed convex hull of a compact set is compact has the property that $\left(E^{\prime}, T_{Q}\right)$ is complete for certain admissible topologies $T_{\mathbb{Q}}$ (including $x\left(E^{\prime}, E\right)$ ). The proof of the Theorem thus holds for such topologies also.

\section{REFERENCES}

1. J. Howard, Mackey compactness in Banach spaces, Proc. Amer. Math. Soc. 37(1973), 108-1 10 .

2. J. L. Kelley and I. Namioka, Linear topological spaces, University Series in Higher Math., Van Nostrand, Princeton, N. J., 1963. MR 29 \#3851.

3. G. Köthe, Topologische linear Räume. I, Die Grundlehren der math. Wi ssenschaften, Band 107, Springer-Verlag, Berlin, 1960; English transl., Die Grundlehren der. math. Wissenschaften, Band 159, Springer-Verlag, New York, 1969. MR 24 \#A411; 40 \# 1750.

4. A. P. Robertson and W. J. Robertson, Topological vector spaces, Cambridge Univ. Press, New York, 1964. MR 28 \#5318.

DEPARTMENT OF MATHEMATICS, HOFSTRA UNIVERSITY, HEMPSTEAD, NEW YORK 11550 